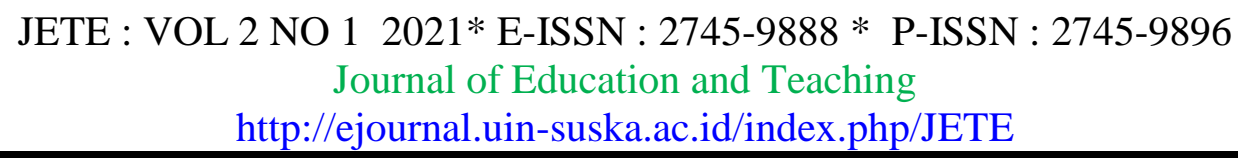

\title{
HADITS TENTANG FITRAH DAN IMPLIKASINYA DALAM PERKEMBANGAN MANUSIA
}

\author{
${ }^{1}$ Arnin Agung S. Pd ${ }^{2}$ Dr. Hj. Alfiah,S.Ag. M.Ag

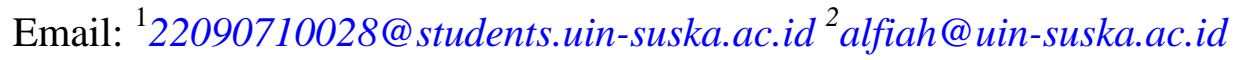

Received: 30 Oktober 2019; Accepted 28 Mei 2021; Published 31 Mei 2021

Ed 2021; 2(1): 116-122

\begin{abstract}
ABSTRAK
Penelitian ini merupakan penelitian kajian pustaka. Penelitian ini bertujuan untuk membahas tentang takhrij hadis yang berjudul tentang fitrah dan amplikasinya dalam perkembangan manusia. Secara khusus, tulisan ini membahas tentang fitrah seorang anak ketika sebelum dilahirkan kedunia, dan perkembangannya ketika hidup didunia dalam beragama. Hadis yang penulis gunakan dalam tulisan ini adalah hadis yang diriwayatkan oleh Bukhari dan lainnya. Dimana hadis tersebut adalah hadis yang sahih dan memiliki syahid dan mutabi' sebagai penguat hadis tersebut Tulisan ini diproyeksian sebagai tinjauan bahwa agama (islam) itu fitrah dan bukan merupakan dari keturunan. Data dikumpulkan melalui dokumentasi literature dan dianalisis dengan analisis deskriptif.
\end{abstract}

Kata Kunci : Hadis, Ftrah, Manusia

\begin{abstract}
This paper discusses the hadith takhrij entitled about fitrah and its application in human development. Specifically, this paper discusses the nature of a child before being born into the world, and its development when living in the world in religion. The hadith that the author uses in this paper is the hadith narrated by Bukhari and others. Where the hadith is a hadith that is valid and has martyrdom and mutabi 'as reinforcing the hadith. This paper is projected as a review that religion (Islam) is natural and not inherited.
\end{abstract}

Keywords: Hadith, Ftrah, Human

\section{PENDAHULUAN}

Hadits dalam ruang perkembangan ilmu-ilmu keislaman merupakan kajian yang tidak pernah berhenti untuk dibicarakan. Hadits dianggap sebagai sumber hukum dan ajaran Islam kedua setelah al Qur'an. Perkembangan masyarakat terus bergulir dengan cepat dan problematika kehidupan semakin kompleks. Problematika kehidupan manusia yang dihubungkan dengan agama memerlukan sebuah penyelesaian yang melibatkan proses refleksi terhadap ajaran-ajaran agama. Pada ruang dan wacana seperti ini, posisi hadits dijadikan sebagai sebuah sumber hukum dalam rangka menyelesaikan problematika yang dihadapi, di samping al-Qur'an dan pemikiran-pemikiran ulama Islam dari klasik, modern hingga kontemporer. Upaya umat Islam dalam menjelaskan sikap islam atau Rasul SAW, 
mengenai suatu masalah harus berpegang pada hadis shahih dan hasan bukan pada hadis dhaif, apa lagi pada hadis maudlu (Yusuf Qardawi, 1993:3) Maka patutlah bagi kita umat Islam untuk mentakhrij Hadis-hadis Nabi kita SAW, untuk mengetahui mana hadis yang sahih dan mana hadis yang maudu' (palsu). Semoga makalah ini dapat bermanfaat bagi kita.

\section{METODOLOGI}

Penelitian ini merupakan penelitian kajian pustaka. Data dikumpulkan melalui dokumentasi literature dan dianalisis dengan analisis deskriptif.

\section{HASIL DAN PEMBAHASAN}

Sanad dan Matan Hadis

Hadis Rasulullah SAW tentang Fitrah Manusia

$$
\begin{aligned}
& \text { حدثنا عدنان أخبرنا عبد الله أخبرنا يونوس عن الزهري أخبرني أبو سلمة بن عبد الرحمن أن أن أبا هريرة رضي الله عنه قال }
\end{aligned}
$$

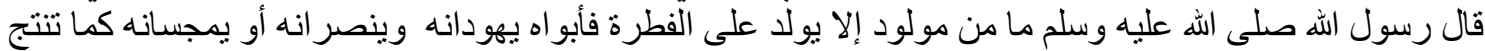

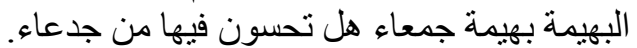

Artinya: Abdan menceritakan kepada kami (dengan berkata) 'Abdullah memberitahukan kepada kami (yang berkata) Yunus menceritakan kepada kami (yang berasal) dari Al-Zuhri (yang menyatakan) Abu salamah bin 'Abd al-Rahman memberitahukan kepadaku bahwa Abu Hurairah berkata : Rasulullah saw bersabda: Setiap anak lahir (dalam keadaan) Fitrah, kedua orang tuanya (memiliki andil dalam)menjadikan anak Yahudi, Nasrani, atau bahkan beragama Majusi,sebagaimana binatang ternak memperanakan seekor binatang (yang sempurna anggota tubuhnya). Apakah anda melihat anak binatang itu ada yang cacat (putus telinganya atau anggota tubuhnya yang lain)? (Imam al-Bukhâri, 1987:456) Dalam Riwayat lain diantaranya:

Riwayat Muslim

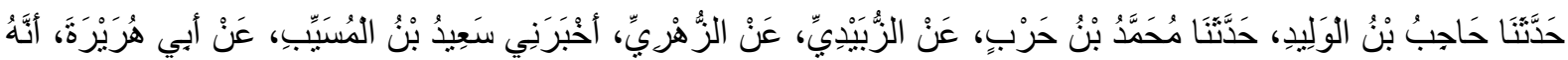

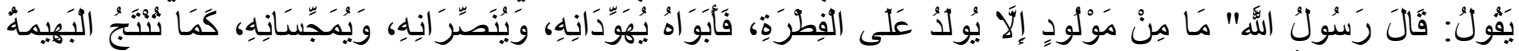

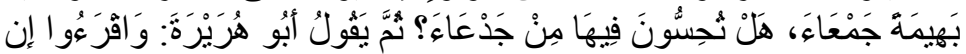

Artinya :Hâjib bin al-Walid menceritakan kepada kami (dengan mengatakan) Muhammad bin harb menceritakan kepada kami (yang berasal) dari al-Zubaidi (yang diterima) darfi al-Zuhri (yang mengatakan) Sa'id bin al-Musayyab memberitahukan kepadaku (yang diterima) dari Abu Hurairah bahwa ia berkata, Rasulullah saw bersabda: "Setiap anak lahir (dalam keadaan) fitrah, kedua orang tuanya (memiliki andil dalam) menjadikan anak beragama Yahudi, Nasrani, atau bahkan beragama Majusi, sebagaimana binatang ternak memperanakkan seekor binatang (yang sempurna anggota tubuhnya). Apakah anda mengetahui di antara binatang itu ada yang cacat/putus (telinganya atau anggota tubuhnya

Skema Jalur Sanad

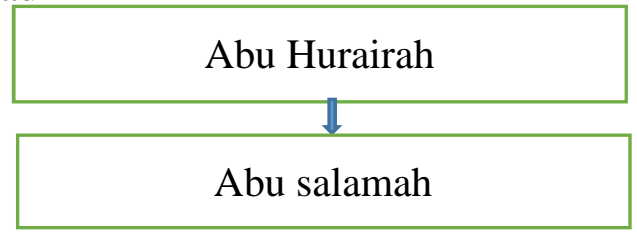




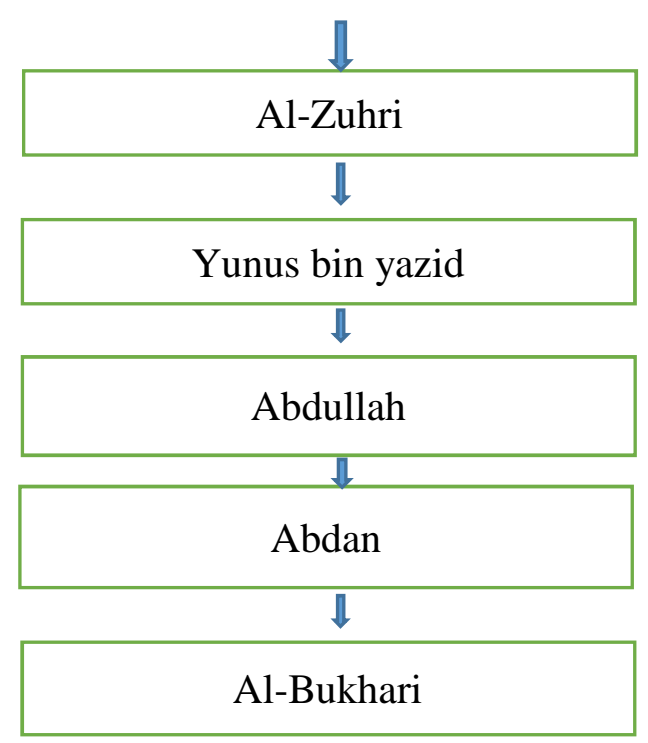

\section{Biografi Perawi}

\section{Abu Hurairah $(19 \mathrm{H}-59 \mathrm{H})$}

Nama lengkapnya adalah 'Abd al-Rahman bin Shakhr al-Dausi alYamani. Pada masa Jahiliyah, nama Abu Hurairah tidak dikenal secara jelas, bahkan menurut beberapa riwayat, ia memiliki banyak nama. Menurut satu riwayat ia bernama 'Umair bin 'Amir bin 'Abd. Riwayat lain mengatakan 'Abd 'Amr bin 'Abd Ghanam. Ada juga yang berpendapat 'Abd alSyams. Pada masa Islam, namanya adalah 'Abdullah, tetapi ada yang menyebutnya 'Abd alRahman. Ia kemudian diberi gelar Abu Hurairah oleh Nabi saw, karena kecintaannya pada kucing (Ibn al-Atsir, Usd al-Ghabah (Mesir: Dar al-Fikr, tt.), Juz 3, hlm 258)

Abu Hurairah termasuk salah seorang sahabat yang paling banyak meriwayatkan hadis, yang menurut Imam al-Bukhari 800 orang sahabat dan tabi'in meriwayatkan hadis darinya. Menurut penuturan al-Haitsam bin 'Ady, ia meninggal pada tahun $58 \mathrm{H}$. Sedangkan menurut al-Waqidi, ia meninggal dunia pada tahun $59 \mathrm{H}$ (Ibn al-Atsir, Usd al-Ghabah... hlm. 253)

Berdasarkan kaidah umum dalam ilmu hadis, al-shahabah kulluhum 'udul, maka dia dimasukkan ke dalamnya yang berarti keadilan dan kedhabitannya dapat diterima.

2. Abu Salamah (w. $94 \mathrm{H})$

Nama lengkapnya adalah 'Abdullah bin 'Abd al-Rahman bin 'Auf alZuhri (Ibn Hajar al-'Asqalani, 1995:531-532.) Ia termasuk salah seorang tabi'in yang menetap dan meninggal di Madinah pada tahun $94 \mathrm{H}$. Guru Abu Salamah diantaranya adalah Abu Hurairah, Ibrahim bin 'Abdullâh bin Qaridl, Abu al-Radad, Abu Sufyân bin Sa'id bin Mughirah, Usamah bin Zaid bin Haritsah, Abu Hurairah, dan lain-lain. Murid Abu Salamah antara lain adalah Ibrahim bin 'Ablah Syamr bin Yaqdlan, Ibrahim Sa'ad bin Ibrahim, Ismail bin Umayyah, Muhammad bin Muslim bin Syihab al-Zuhri, dan lainlain. Penilaian kritikus hadis terhadapnya dapat dilihat sebagaimana yang disampaikan oleh Abû Zar'ah al-Râzi yang mengatakan bahwa ia adalah tsiqah (orang yang terpercaya), 8 imam (panutan). Ibn Sa'ad menilainya tsiqah. Al-Dzahabi menilainya ahad al-aimmah (salah seorang imam/panutan). Adapun Ibn Hibban memasukkannya ke dalam kitab AlTsiqât-nya.

3. Al-Zuhri $(50 \mathrm{H}-124 \mathrm{H})$

Nama lengkapnya adalah Muhammad bin Muslim bin 'Ubaid Allâh bin bin 'Abd Allâh bin Syihâb bin 'Abdillâh bin al-Hârith bin Zuhrah bin Kilâb bin Murrah al- 
Quraisyi al-Zuhri al-Madani (Ibn Hajar al-'Asqalani, 1995:696-697). Ia adalah salah seorang Imam dan ulama Hijaz dan Syam. Ia meninggal pada tahun $124 \mathrm{H}$. Gurunya antara lain adalah 'Abdullâh bin 'Umar bin al-Khaththâb, 'Abdullâh bin Ja'far, Rabî'ah bin 'Abbâd, al-Mismar bin Makhramah, Anas, Jâbir, 'Abdullâh bin 'Âmir bin Rabî'ah, Abû al-Thufail, dan lain-lain. Muridnya di antaranya adalah 'Athâ' bin Abi Rabâh, Abu al-Zubair alMakki, 'Umar bin 'Abd al-'Azîz, 'Amr bin Dînar, al-Auza'i, Shâlih bin Kaisân, Yunus bin Yazid, Ma'mar, al-Zubaidi, dan lain-lain. Penilaian kritikus hadis seperti Ibn Sa'ad menyatakan bahwa al-Zuhri adalah tsiqah, al-Khathîb mengatakan dia adalah mutqin (orang yang meyakinkan), 'alim (orang yang ahli), dan hafidz (orang yang hafal). Ibn Hibban memasukkannnya ke dalam kitab Al-Tsiqât-nya.

4. Yûnus bin Yazîd (w. 159 H)

Nama lengkapnya adalah Yûnus bin Yazîd bin Abi al-Najjâd. Ia juga dikenal dengan Ibn Musykân bin Abi al-Najjâd. Gurunya antara lain adalah Abu 'Ali bin Yazid, al-Zuhri, Nâfi' (maula Ibn 'Umar), Hisyâm bin 'Urwah, 'Ikrimah, 'Umârah bin Ghaziyyah, dan lainlain. Muridnya antara lain Jarîr, 'Amr bin al-Hârits, 'Anbasah bin Khâlid bin Yazid, ('Abdullah) Ibn al-Mubarak, al-Laits, al-Auza'i, Sulaiman bin Bilâl, dan lain-lain. Penilaian kritikus hadis terhadapnya antara lain dikatakan oleh 'Abdullah bin al-Mubarak yang menilainya kitabuhu shahih (kitabnya baik/valid), Yahya bin Ma'în mengatakan tsiqah (orang yang terpercaya), alNasâ'i menyatakan tsiqah, al-'Ijli mengatakan tsiqah, dan Abu Zur'ah menilainya la ba'sa bihi (dia tidak bermasalah/orang yang tidak cacat).

5. 'Abdullah (w. 181 H)

Nama lengkapnya adalah Abu 'Abd al-Rahmân 'Abd Allâh bin alMubârak bin Wâdhih al-Handlali al-Tamimi al-Marwazi. Gurunya antara lain Sulaimân al-Taimi, Humaid al-Thawîl, Ismâ'îl bin Abi Khâlid, Yahya bin Sa'îd al-Anshâri, Sa'ad bin Sa'îd al-Anshâri, Ibrâhim bin Abi 'Ablah, Khaldah Khâlid bin Dînâr, 'Âshim al-Ahwal, Yunus bin Yazîd, dan lain-lain. Muridnya antara lain al-Tsauri, Ma'mar bin Râsyid, Abu Ishâq alFazâri, Ja'far bin Sulaimân al-Dhab'i, Baqiyyah bin al-Walîd, Ibn 'Uyainah, dan lainlain. Penilaian ulama terhadapnya disampaikan oleh al-'Ijli yang menilainya tsiqah (orang yang terpercaya), Yahya bin Ma'in juga menilainya tsiqah, dan Ibn Hibbân memasukkannya ke dalam kitabnya al-Tsiqât

6. 'Abdan (w. 221 H)

Nama lengkapnya adalah 'Abd Allâh bin Utsmân bin Jabalah bin Abi Rawwâd alAzdi al-'Ataki, yang kemudian diberi gelar 'Abdân. Ia meninggal pada tahun $221 \mathrm{H}$. Gurunya antara lain ayahnya yang bernama Abu Hamzah al-Sukari, Yazîd bin Zurai', Ibn al-Mubârak, Jarîr bin 'Abd al-Hamîd, Syu'bah, Hammâd bin Zaid, Isâ bin 'Ubaid, Muslim bin Khâlid al-Zanji, dan lain lain.

Muridnya antara lain al-Bukhari, Muhammad bin 'Abd Allâh bin Quhzâdz, Ahmad bin Muhammad bin Syibawaih, Muhammad bin 'Ali bin al-Hasan, dan lain-lain Penilaian ulama terhadapnya menurut pernyataan Abu Rajâ' Muhammad, dia adalah tsiqah ma'mun (orang terpercaya lagi kredibel), Imam al-Hâkim mengatakan dia adalah imam ahl al-hadits bi baladih (imam ahli hadis di negaranya). Imam al-Bukhari meriwayatkan hadis darinya sebanyak 110 hadis.Ibn Hibban memasukkannya ke dalam kitabnya alTsiqât.

7. Imam Bukhari

Nama lengkapnya adalah Muhammad bin Ismail bin Ibrahim bin al-Mughirah bin Bardizabah, Abu abdillah al-Bukhari. Diantara guru dan murid beliau adalah Ubaidillah bin Musa, Muhammad bin Abdillah al-Anshariy, 'Affan, Abi Ashim al-Nabil, Ibnu muslim, Al-Nasa'iy, Abu Zar'ah, Abu Hatim, Muhammad bin Abdillah al-Hadharamiy, Ibnu Khuzaimah, Al-Fadhl bin al-Abbas al-Raziy dan lain-lain (Ibn Hajar al-'Asqalani, 
Tahdzîb al-Tahdzîb, juz 7.(Dar Alfkr-Beirut Libanon,1995)h41-42). Bakir bin Numair berkata: Aku mendengar al-Hasan bin al-Husain berkata: Saya melihat Muhammad bin Ismail (Bukhari) adalah orang yang tua, badannya tidak tinggi dan tidak pula pendek, dilahirkan pada bulan syawal tahun $194 \mathrm{H}$ dan meninggal pada hari sabtu bulan syawal tahun $256 \mathrm{H}$ dalam usia 62 tahun kurang 13 hari.

Analisis Kualitas Sanad dan Matan

Dalam menentukan kualitas sebuah hadis, para ulama hadis mengemukakan 5 (lima) kriteria kesahihan hadis, yaitu: 1) sanadnya bersambung; 2) perawinya adil; 3) perawinya dhabith; 4) terhindar dari syudzudz, (kejanggalan), dan 5) terhindar dari illat (cacat).

Setelah melihat uraian di atas maka dapat disimpulkan :

Bahwa hadits tentang setiap anak dalam keadaan fitrah adalah berkualitas shahih dikarenakan telah memenuhi syarat-syaratnya yaitu sanadnya bersambung, Para perawinya 'adil dan dhabith (kuat hafalan-nya), Tidak mengandung unsurunsur syadz dan tidak mengandung kecacatan ('illat) yang dapat merusak keabsahan hadits.

\section{A. Pemahaman Hadis dan implikasinya dalam Perkembangan Manusia}

Dalam pengertian yang sederhana istilah definisi fitrah sering dimaknai suci dan potensi. Secara etimologis, asal kata fitrah/fitroh/pitrah berasal dari bahasa Arab, yaitu fitrah “ "jamaknya fithar " ,"yang suka diartikan sebagai perangai, tabiat, kejadian, asli, agama, ciptaan.16 Menurut Quraish Shihab, istilah fitrah diambil dari akar kata al-fithr yang berarti belahan. Dari makna ini lahir makna-makna lain, antara lain pencipta atau kejadian (M. Quraish Shihab, 1996:283).

Dalam gramatika bahasa Arab, sumber kata fitrah wazannya fi'lah, yang artinya alibtida', yaitu menciptakan sesuatu tanpa contoh. Fi'lah dan fitrah adalah bentuk masdar (infinitif) yang menunjukkan arti keadaan. Demikian pula menurut Ibnu Katsir dan Ibn alQayyim karena fitir artinya menciptakan, maka fitrah berarti keadaan yang dihasilkan dari penciptaan itu. lafadz fitrah tidak pernah dikemukakan dalam al-Quran dalam konteksnya selain dengan manusia (Murtadha Muthahhari, Fitrah (Jakarta: Paramadina, 1989), cet. ke-1, hlm. 6- 17)

Kesahihah sanad (shahîh al-Isnâd) belum menjadi jaminan bagi kesahihan matan (shahîh al-matn). Sebuah hadis yang sanadnya sahih muttasil dapat saja memiliki matan yang tidak sahih, dan demikian juga sebaliknya. Penelitian kedua aspek (sanad dan matan) menjadi penting untuk menemukan validitas dan otentisitas sebuah hadis.

Meskipun al-Bukhari dan Imam Muslim pada hadis yang dijadikan titik tolak kajian dalam buku ini menggunakan kalimat mâ min maulûd illâ yûlad, tetapi dalam hadis yang lain, al-Bukhari dan Muslim juga memakai kalimat kullu maulûd yûlad. Imam Tirmidzi yang berbeda redaksi dengan menggunakan kata al-millah,Perbedaan redaksi atau lafal yang demikian merupakan sesuatu yang wajar dalam periwayatan hadis, karena kebanyakan periwayatan hadis dilakukan secara makna (al-riwâyah bi al-ma'na).

Oleh sebab itu, perbedaan lafalz menjadi sesuatu yang tidak dapat dihindari dalam periwayatan hadis. Oleh sebab itu, perbedaan lafalz dalam hadis tentang fitrah tidak terjadi syudzuz (janggal) dan illah (cacat) (Ibnu Hajar al-Asqalani, Fathul Barri (penjelasan kitab Shahih al-Bukhari). Terj. Amiruddin, Jilid VII, Jakarta: Pustaka Azzam, 2008, hlm 344). Abu Hurairah ketika meriwayatkan hadis tentang fitrah tersebut mencantumkan pesan dia dengan ziyâdah pada akhir matan hadis "jika kamu menghendaki maksud kata fitrah itu, 
maka rujuklah kepada Q.S. al-Rum (30) : 30. B. Kata al-millah dalam riwayat al-Tirmidzi yang diartikan sama dengan fitrah memiliki dalalah arti millah al-Islam (agama Islam).

Agama itu bukanlah sebuah keturunan, melainkan fitrah yang telah dianugrahkan oleh allah subhanahu wata'ala kepada setiap hambanya.

Para ulama mutaakhirin menguatkan bahwa yang dimaksud fitrah tersebut adalah Islam karena Q.S. al-Rum (30): 30 adalah kalimat"fitrat Allah" dalam arti Idâfah Mahdhah yang memerintahkan Nabi saw untuk selalu tetap pada fitrah. Oleh karena itu kata fitrah berarti Islam. Dalam kitab Syarah Shahih Muslim karangan al-Nawawi disebutkan bahwa sebagian besar ulama berpendapat anak Muslim yang meninggal, dia akan masuk ke surga. Sedangkan anak-anak orang musyrik yang mati sewaktu kecil, ada tiga kelompok pendapat: 1) kebanyakan mereka mengatakan bahwa mereka (anak-anak musyrik itu) masuk ke dalam neraka; 2) sebagian mereka tawaqquf (tidak meneruskan persoalan tersebut); 3) masuk surga.

Pendapat terakhir ini didukung dan dibenarkan oleh al-Nawawi. Argumentasi pendapat ketiga ini adalah berdasarkan hadis Nabi saw ketika sedang melakukan Isrâ' dan Mi'râj, dia melihat Nabi Ibrahim as di dalam surga dan di sekelilingnya anak-anak manusia. Para sahabat bertanya: "apakah mereka anak-anak orang musyrik ? Nabi menjawab: Ya, mereka itu anakanak orang musyrik. Beberapa pandangan konsep filsafat yang mejelaskan tentang teori yang mempengarui perkembangan manusia.

1. Konsep Fatalis-Pasif

Setiap individu, melalui ketetapan Allah SWT adalah baik atau jahat secara asal, baik ketetapan semacam ini terjadi secara semacamnya atau sebagian sesuai denhan rencana Tuhan. Faktor-faktor eksternal tidak berpengaruh terhadap penentuan nasib seseorang karena setiap indidvidu terikat dengan ketetapan yang telah ditetapkan sebelumnya oleh Allah SWT (Maragustan Siregar, 2010: 191)

2. Konsep Postif-Aktif

Bawaan dasar atau atau sifat manusia sejak lahir adalah berkarakter baik, kuat dan aktif, sedangkan lingkunganlah yang membelenggu manusia sehingga iya menjauh dari sifat bawaannya (Aksidental).

3. Konsep Dualis-Aktif

Yakni manusia memiliki dua sifat ganda yang sama kuatnya. Sifat baik dan buruk, tergantung kedekatan manusia terhadap lingkungan yang baik atau buruk. Jika ia dekat dengan teman berkarakter baik, maka seseorang akan mengambil sifat baiknya dan sebaliknya. Penanaman kebiasaan positif sangat penting untuk diupayakan sejak kecil agar karakter atau sifat baik itu lebih kuat.

\section{SIMPULAN}

Allah telah menciptakan manusia dengan tujuan agar manusia menjadi Hamba Allah yang pandai mengabdi (ibadah) kepada Allah SWT. Firman Allah SWT: Dan Aku tidak menciptakan jin dan manusia melainkan supaya mereka menyembah-Ku. Allah Al-Khaliq (Pencipta) dan Al-Mushowwir (Pendesain), pasti telah mendesain penciptaan manusia baik dari bahan dan prosesnya, sedemikian rupa agar hasil akhirnya lahir suatu makhluk manusia yang bisa mengabdi (ibadah) kepada Allah SWT. Jadi fitrahnya manusia adalah mengabdi atau beribadah kepada Allah SWT. Karena fitrahnya manusia adalah mengabdi (ibadah) kepada Allah SWT, maka manusia dengan struktur jasmani dan rohaninya pasti bisa dipakai untuk mengabdi (ibadah) kepada Allah. Rohani dan jasmani manusia pasti cocok dan pas dipakai untuk beribadah. Sebaliknya jika dipakai maksiat (membangkang) kepada Allah pasti tidak nyaman, dan dipastikan pasti bakal cepat rusak dan celaka. Sungguh kecelakaan manusia adalah karena penyimpangan dari "fitrahnya". 


\section{DAFTAR REFERENSI}

al-Atsir, Ibn, Usd al-Ghabah Juz 3, Mesir: Dar al-Fikr, tt.

Hajar al-‘Asqalani, Ibn, Tahdzîb al-Tahdzîb Mesir: Mu’assasah al-Risalah, 1995, Juz IV

Ibnu Hajar, 2008, Fathul Barri (penjelasan kitab Shahih al-Bukhari). Terj. Amiruddin, Jilid XXIII, Jakarta: Pustaka Azzam

Murtadha Muthahhari, Fitrah, Jakarta: Paramadina, 1989.

Muslim, Imam, Shahih Muslim, Beirut: Dar Ihya' al-Turats al-'Arabi, t.t.. Kitab alIman, Bab al-Du'a' ila al-Syahadatain wa Syara'i’ al-Islam, Hadis Nomor 19, Jilid I

Qardawi, Yusuf, 1993Keutamaan Ilmu dalam Islam, Jakarta: Pustaka PanjiMas. al-Bukhari, Imam, Shahih al-Bukhari, Kitab al-Zakah, Bab La tu'khadz karaim amwal al-nas fi al-shadaqah, Hadis Nomor 1389, Jilid II, Beirut: Dar Ibn Katsir, 1987.

Shihab, M. Quraish, Wawasan Al-Qur'an, Bandung: Mizan, 1996.

Siregar, Maragustan, 2010,Mencetak Pembelajar Menjadi Insan Paripurna, (Filsafat Pendidikan Islam), Yogyakarta: Nuha Litera.

https://makalahnih.blogspot.com.hadis-nabi-tentang-fitrah-dan.html diunggah pada 07 Juli 2014 